\title{
Le coton, sa culture et son utilisation selon les sources arabes médiévales
}

The cultivation and uses of cotton in medieval Arab sources

Jean-Charles Ducène

\section{(2) OpenEdition}

\section{Journals}

Édition électronique

URL : http://journals.openedition.org/ethnoecologie/4098

DOI : $10.4000 /$ ethnoecologie.4098

ISSN : 2267-2419

Éditeur

Laboratoire Eco-anthropologie et Ethnobiologie

\section{Référence électronique}

Jean-Charles Ducène, "Le coton, sa culture et son utilisation selon les sources arabes médiévales », Revue d'ethnoécologie [En ligne], 15 | 2019, mis en ligne le 30 juin 2019, consulté le 31 octobre 2019. URL : http://journals.openedition.org/ethnoecologie/4098; DOI : 10.4000/ethnoecologie.4098

Ce document a été généré automatiquement le 31 octobre 2019

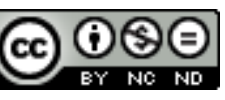

Revue d'ethnoécologie est mis à disposition selon les termes de la licence Creative Commons Attribution - Pas d'Utilisation Commerciale - Pas de Modification 4.0 International. 


\section{Le coton, sa culture et son utilisation selon les sources arabes médiévales}

The cultivation and uses of cotton in medieval Arab sources

Jean-Charles Ducène

\section{Introduction}

1 Pour l'Antiquité, les sources écrites et l'archéologie témoignent de la présence de coton en Mésopotamie (Quillien, ce volume). L'archéologie a bien révélé la présence du coton en péninsule Arabique alors que Théophraste (IV $\mathrm{e}$. AEC) en parle justement pour Bahrein, dans le golfe Persique (Théophraste, Recherches sur les plantes II. IV. 7, ed. 1989). Au début du IV siècle, la stèle d'Ezana (ca 325-356) en indique la présence en Nubie, ce qui a été également confirmé par l'archéologie. Par ailleurs, le coton est cultivé au $\mathrm{II}^{\mathrm{e}}$-IV $\mathrm{V}^{\mathrm{e}}$ siècle dans les oasis égyptiennes (Bagnall 1997: 40 ; pour les sources archéologiques de la péninsule arabique et nord-est africaine, voir l'introduction et les différents articles de ce volume). On le repère ensuite difficilement durant l'Antiquité tardive et il faut attendre la conquête arabe pour qu'il réapparaisse en Égypte, où il reste néanmoins rare (Britton 1938: 23 et 28, note 13; Gayraud 1994; Cortopassi \& Gayraud 2008). À telle enseigne que le prosateur arabe al-Tha'alibì (m. 1038) a écrit

« on sait que le coton appartient au Hurāsān et le lin à l'Égypte. Les vêtements en coton et en lin faits ailleurs n'égalent pas en quantité ceux produits dans ces deux régions » (Al-Tha'ālibī, éd. $1968: 120)$.

2 Ainsi, la culture du coton et son usage textile s'avèrent essentiellement présents à la périphérie du domaine arabe et musulman au début de l'époque médiévale, mais lorsque les sources arabes deviennent disponibles la situation a changé. Ce sont ces sources que nous voudrions ici interroger en focalisant notre attention sur des ouvrages techniques pour percevoir quelle terminologie tournait autour de cette 
culture, si ces lexèmes étaient arabes ou non, et si dans ce cas leur origine pouvait indiquer un transfert de technique.

3 Ces sources sont des ouvrages arabes de botanique, d'agronomie, de lexicographie et de géographie ainsi que des calendriers et elles nous permettent d'approcher plusieurs aspects de la présence et de la production du coton dans le domaine arabe médiéval. Cependant, entre le $\mathrm{v}^{\mathrm{e}}$ siècle - période à laquelle les sources antiques et l'archéologie cessent de nous informer - et le $\mathrm{IX}^{\mathrm{e}}$ siècle qui voit l'apparition des témoignages arabes, l'évolution de la situation est peu documentée. Néanmoins, dès qu'elles apparaissent, les sources arabes montrent un développement de la culture du coton relativement ancien.

4 Évidemment, l'étude lexicographique du vocabulaire que les auteurs utilisent, renseigne aussi sur la richesse lexicale entourant la plante, ses produits et leur traitement. Quant aux agronomes et aux botanistes, ils fournissent des informations sur la culture ou sur plusieurs aspects de la plante, alors que les calendriers en précisent les phases de culture selon les régions auxquelles ils appartiennent. Enfin, la littérature commerciale informe des caractéristiques du négoce de la matière première ou des textiles alors que les textiles conservés dans des institutions muséales peuvent confirmer ou préciser ces informations.

\section{Étude terminologique}

\section{Les termes du champ lexical du coton en arabe et dans les langues voisines}

5 Le terme arabe quṭn qui est attesté dès le $\mathrm{VII}^{\mathrm{e}}$ siècle reste d'une étymologie inconnue (Figure 1). Il apparaît ainsi dans un vers des poètes Dahlab ibn Quray‘ et Labīd (m. 660) généralement pour jouer sur la forme du fruit de coton ou comme métaphore de tissu (Ibn Manẓūr, Lisān XI. 232, éd. 1997).

Figure 1 : Transcription des termes akkadien, hébreu médiéval et arabe désignant le coton

\begin{tabular}{c|c|c}
\multicolumn{1}{c|}{ Akkadien } & Hébreu médiéval & Arabe \\
\hline kiținnû (IXe s. AEC) & & quțn (Vlle s.)
\end{tabular}

Le terme akkadien, plus précisément néo-assyrien, kiținnû qui apparaît au IX ${ }^{\mathrm{e}}$ siècle BCE (Zawadzki 2006: 24-28; Muthukumaran 2016: 98-108; Quillien, ce volume) n'a pas d'étymologie sémitique claire et univoque. La forme arabe quṭn - attestée dans des vers censés remonter au $\mathrm{VII}^{\mathrm{e}}$ siècle - pourrait-elle en provenir ? L'étymologie akkadienne est peu probable car une consonne occlusive vélaire en akkadien ne prend pas l'emphatisation en araméen et en arabe (ex. akk. kalū «tout », syr. kol, ar. kull). Le rapprochement avec le terme kattān, «lin », qui est lui pansémitique (Rolland 2016 : 154; Gignoux 2011: 53), n'est guère envisageable car la différentiation sémantique serait alors passée par l'emphatisation de la première consonne, ce qui n'est pas autrement attesté. Il serait plus vraisemblable d'y voir un emprunt. Fraenkel $(1886,42)$ penchait jadis pour un étymon copte kontion, mais que rien n'est venu confirmer depuis. Muthukumaran (2016) propose avec vraisemblance, pour expliquer tant la 
forme akkadienne que la forme arabe, un emprunt à une des langues dravidiennes (tamoul : kintan, kamada : ginta ; télugu : gințemu).

7 Quoi qu'il en soit, les lexicographes arabes médiévaux n'ont pas ressenti le lexème comme étranger à l'arabe. Et le terme est entré dans une série de dérivés : al-maqtana : " champ où sont plantés les aqtān ou cotonniers". Le verbe qațtana signifie " commencer à se nouer» en parlant du tronc du cotonnier, la "graine» étant le qațūnā'. Ibn Manẓūr (Ibn Manzūū, Lisān XI. 232, éd. 1997) ajoute que c'est l'appellation utilisée en Iraq. Quant aux termes désignant des opérations techniques comme l'égrenage (halağ), le cardage (nadf) ou la torsion (fatl), ce sont les termes génériques des techniques agricoles et textiles antérieures qui sont repris.

8 L'hébreu médiéval a bien kutna pour coton que Klein (1987: 290) considère comme un emprunt à l'arabe, mais influencé par la prononciation de l'araméen kitan («lin ») et de l'hébreu kutnéh ("tunique») ce qui expliquerait la disparition de l'articulation emphatique à l'initiale (Löw 1924 : 242 ; Klein 1987 : 290)

Le terme est tardivement ( $\mathrm{XIII}^{\mathrm{e}} \mathrm{s}$.) passé en ge ez sous la forme $q^{w}$ oțn mais avec le sens de "soie, tissu", alors que c'est dès la fin du XIII ${ }^{\mathrm{e}}$ siècle que remonte le premier témoignage de la production de cotonnades en Éthiopie (Marco Polo, Livre des Merveilles, éd. 2011 : 492 ; Brzuski 1974 : 67). Cependant, des graines de coton ont été identifiées dans des niveaux archéologiques du $\mathrm{VI}^{\mathrm{e}}-\mathrm{VII}^{\mathrm{e}}$ siècle à Aksoum. Sans témoigner de la production de tissus, elles montrent la présence de la plante avant l'apparition du terme en ge'ez (Boardman 1999: 137-147). On peut remarquer qu'en syriaque c'est le terme palbag qui désigne le coton, il provient du moyen pehlevi pambag, d'où le persan moderne panba et l'arménien bambak (MacKenzie 1971: 64; Ciancaglini 2008: 233; Sokoloff 2009 : 1193). Ce même terme pehlevi a aussi été allégué comme l'étymon d'un des mots qui en chinois désigne le coton (Schafer 1985 : 204-206).

Parallèlement, l'arabe possède également le terme ki/karbās avec pour sens des "textiles en coton", attesté dès le viI ${ }^{e}$ siècle puisqu'un dérivé du terme, le nom de métier, apparaît dans une tradition musulmane attribuée à 'Umar ibn al-Hुațāāb (m. 644) (Ibn Manzūur, Lisān XII. 60, éd. 1997). Le mot, provenant du sanskrit, a une vaste diffusion en Orient, suivant en quelque sorte le produit (Figure 2). Le terme est bien d'origine sanskrite mais, dès son attestation en néo-assyrien sous la forme karpassu (Beaulieu 1989: 71-75), il se répand au Proche-Orient puisqu'on le retrouve en hébreu biblique (Esther, I, 6) et de là dans le Talmud Megillah, en araméen et bien en entendu en syriaque (Sokoloff $2009: 647:$ «fine linen »), en arabe (Ullmann $1970: 117-118)$, avec pour sens non la matière en tant que telle, mais les produits dérivés, textiles en général.

Figure 2 : Transcription des termes désignant le textile en néo-assyrien, hébreu biblique, araméen et syriaque

\begin{tabular}{|c|c|c|c|}
\hline Néo-assyrien & $\begin{array}{l}\text { Hébreu biblique } \\
\text { Talmud Megillah }\end{array}$ & Araméen & Syriaque \\
\hline \multicolumn{4}{|l|}{$\begin{array}{c}\text { karpassu } \\
\text { (253-252 AEC.) }\end{array}$} \\
\hline & $\begin{array}{c}\text { karpas } \\
\text { (Esther, I, 6), ler s. AEC. }\end{array}$ & & \\
\hline & & $\begin{array}{l}\text { karpesa } \\
\text { (non daté) }\end{array}$ & $\begin{array}{c}\text { Kirbas } \\
\text { (non daté }\end{array}$ \\
\hline
\end{tabular}

11 Quoiqu'attesté en araméen, il semble qu'il soit arrivé en arabe par l'intermédiaire du pehlevi car les lexicographes arabes lui prêtent une origine iranienne (Ibn Manẓūr, 
Lisān XII. 60, éd. 1997), sans que l'on puisse dater précisément son entrée dans l'aire iranienne.

\section{Les termes des différentes formes du coton}

On a relevé les termes employés par le botaniste Abū Ḥanīfa al-Dīnāwarī (Dictionnaire botanique) qui donne deux termes : le plant d'un an, al-qawr et le plant plus ancien, alqașm. Il donne encore d'autres termes génériques, cités par l'entremise du lexicographe Abū Masḥal (début Ix ${ }^{e}$ siècle) pour désigner le coton :

- birs ou burs : le terme est un synonyme de coton, qui semble ancien car attesté en poésie ; il provient du persan (Ibn Manẓūr, Lisān I. 376, éd. 1997 ; 'Addi Shir 1990 : 18).

- khurfu' : qui désigne le coton et l'intérieur cotonneux du fruit du 'ushar (Calotropis gigantea/procera). C'est un mot ancien car il apparaît dans un vers d'Ibn Muqabil (vil s.) et Ibn Manzūur spécifie que cela qualifie en particulier le coton qui s'est détérioré dans sa capsule (coll. bur'um). Selon al-Azharī (m. 980), cela désigne aussi le coton égrené (Ibn Manzūur, Lisān IV. 72, éd. 1997 ; Dozy 1881 : I, 364).

- 'uṭb : littéralement "ce qui est doux" quoiqu'à côté du sens général apparait aussi celui de « coton égrené » (Ibn Manẓūr, Lisān IX. 265, éd. 1997 ; Vallet 2010 : 181).

- kursuf, pl. karāsif, est un mot qui, par le persan karshaf, remonte au sanscrit karpas et est déjà attesté au viIe siècle, puisque apparaissant chez le poète Labīd (Löw 1924 : 236 ; 'Addi Shir 1990 : 133).

- țūṭ : synonyme de quțun al-bardī, apparemment un genre de coton (Dozy 1881 : II, 68).

Abū Ḥānifa allègue également que, selon certains, la capsule de coton s'appellerait khaysafüğ, qui est l'arabisation du persan khishafüğ, mais semble cependant être un terme spécialisé puisque les dictionnaires classiques ne le reprennent pas ('Addi Shir $1990: 54)$.

Enfin, huršūn est rapporté dans une comparaison dans un vers anonyme "Comme vole le coton sans fibre (harāshīn) qui est égrené ». Le terme huršūun, pl. harāshīn, désigne ce qui dans le coton «ne porte pas de fibre, que l'on ne peut soumettre à la baguette " (Ibn Manẓūr, Lisān III. 125, éd. 1997).

Cette richesse lexicale ne doit pas faire illusion d'une utilisation courante du coton, cela demeure des termes techniques car le géographe arabe al-Muqaddasī, au $\mathrm{x}^{\mathrm{e}}$ siècle, dans une énumération de synonymes indique les termes quṭn, 'uṭb et kursuf comme désignant le coton, et, pour les noms de métiers, qațțān et hallāğ comme " nettoyeur » ou " fileur » de coton (al-Muqaddasī, Ahsan al-taqāsìm, éd. 1906 : 30). Nous avons vu que le terme 'uṭtb a comme sens premier ce qui est doux, notamment en parlant de laine et par dérivation devient synonyme de coton.

En outre, une rapide enquête dans les papyrus arabes, qui témoignent donc des emplois de la langue vernaculaire en Égypte, montre uniquement des occurrences du terme quț, et ceci à partir de l'an 900. On doit donc supposer que les autres termes sont à considérer comme des mots savants ou littéraires, pas forcément en usage dans le milieu des marchands.

17 Quant au terme ki/karbās en arabe, qui provient du sanscrit où il désigne le coton, il élargit son sens pour qualifier d'abord un vêtement en coton blanc, puis, moins couramment, le coton lui-même (Bulliet 2011 : 8 ; Rolland 2016:165; Ibn Manẓūr, Lisān XII. 60, éd. 1997). Il est ressenti comme un emprunt au persan, mais pleinement intégré 
puisqu'il a donné le nom du vendeur de ce vêtement, karābisī. Dans le sens de « coton ", il apparait dans des traditions musulmanes ou hadith (vII ${ }^{\mathrm{e}}$ s.), ce qui indique son entrée précoce en arabe.

Les dictionnaires ultérieurs enregistrent d'autres termes relatifs au travail de la fibre. Le terme de kirbāl est enregistré avec le sens d'archet avec lequel on nettoie les graines de coton. La forme ghirbāl est aussi attestée et serait à rapprocher du latin cribellum, « crible, tamis » (Rolland $2016: 135)$. C'est un synonyme de mindaf, qui lui est construit sur la racine nadafa qui a pour sens premier « secouer le coton à l'aide de l'archer et le carder ». On a aussi le nom d'outil mitraq, avec le sens premier d'« objet que l'on utilise pour frapper ", "baguette ». Le mot apparaît dans un vers "Comme s'envolent les bourres du coton secouées ».

\section{La terminologie des étoffes et des vêtements en coton}

19 Un grand nombre de termes apparaitt pour décrire des types de toiles tissées à partir du coton, mais il est difficile d'en connaître la réalité matérielle (Miquel 1975 : 432-433). Soulignons un usage rare mais certain au xe siècle: être le support d'une carte géographique (al-Muqaddasī, Ahssan al-taqāsīm, éd. 1906: 6). Les termes les plus répandus sont :

- zanbaft : étoffe produite à Nasa, au Hurūāān (al-Muqaddasī, Aḥsan al-taqāsīm, éd. 1906 : 324 ; Dozy 1881 : 102)

- zandaniği: type de tissu particulier, qui tirait son nom du village où il était tissé (Serjeant 1972: 99-100)

- banbuziyya : étoffe produite à Nasa au nord de l'Iran. André Miquel rapproche le terme du persan penbé "coton" (al-Muqaddasī, Aḥsan al-taqāsìm, éd. 1906 : 324 : 324 ; Miquel $1980: 433)$

- āranğ: "le coloré" produit au Hुwārizm, du persan arang, "couleur » (al-Muqaddasī, Ahsan al-taqāsìm, éd. $1906: 325$; Serjeant 1972 : 105)

- sabaniyyat : répandu à Kābul, en Arménie et en Azerbaydjan. Pour Ibn Ḥawqal, c'était un vêtement en coton (Ibn Ḥawqal, Kitāb șūrat al-ard éd. 1939 : 450 ; Ibn Manẓūr, Lisān VI. 165, éd. 1997 ; Dozy 1881 : 230).

- al-malāham : dans un premier temps, un produit provenant de Merw, avant de devenir un terme spécifique désignant un type d'étoffe (Al-Muqaddasī, Ahsan al-taqāsīm, éd. $1906: 324$; Dozy $1881: 530$ ).

- Baghdad, Merw et Wịdār, au Khurāsān, ont donné leur nom à des tissus de coton (Miquel $1980: 433$; Serjeant $1972: 89,97,110$ )

\section{Les attestations de la présence de la culture et l'artisanat du coton}

Il est à souligner que le coton durant l'Antiquité est sporadiquement attesté autour des territoires au cœur desquels il pénètre à l'époque médiévale, selon des modalités variées. 


\section{Dans la péninsule arabique et en Nubie} 1995 : 70 ; Lombard 2002 : 61-79; Bouchaud 2015). Cependant, le détail nous échappe comme toute estimation quantitative, car nous devons l'enregistrement de la présence de plantations de coton et de la manufacture des cotonnades essentiellement aux géographes arabes dont l'information concerne d'abord le $\mathrm{x}^{\mathrm{e}}$ siècle, les renseignements se font moins denses par la suite selon les lieux. La conséquence est double : d'abord les dynamiques et les mouvements qui aboutissent à la situation qui nous est décrite au $\mathrm{x}^{\mathrm{e}}$ siècle nous échappent et par la suite l'éclairage est plus parcellaire. Quoi qu'il en soit, il est manifeste que la culture du coton est présente depuis longtemps au nord-est et au sud-est de l'Iran lorsqu'elle nous est dépeinte au $\mathrm{x}^{\mathrm{e}}$ siècle et qu'elle s'est implantée en Jazireh (Haute-Mésopotamie) ainsi que dans le Bas-Iraq, depuis l'Iran. De la Jazireh, le mouvement a atteint la Syrie. En Iran et au Proche-Orient, on est passé par endroit de la satisfaction de besoins locaux à la culture de rente quand une industrie textile s'y est implantée et la production commercialisée.

«L'île produit aussi en abondance, paraît-il, des cotonniers arborescents ; ceux-ci ont une feuille qui ressemble un peu, en petit, à celle de la vigne et ils portent, au lieu d'un fruit, le réceptacle du coton, gros comme un faux abricot, bien fermé; le moment venu, ce réceptacle s'ouvre tout grand et on arrache le coton dont on tisse plantes II, IV, 7, éd. 1989).

jusqu'à la période d'abandon du site $\mathrm{au} \mathrm{IV}^{\mathrm{e}}-\mathrm{V}^{\mathrm{e}}$ siècle, des graines de coton ont été identifiées dans un contexte résidentiel (Bouchaud et al. 2018). À la même époque et plus précisément pour le III $^{\mathrm{e}}$ siècle, dans l'est de la péninsule Arabique, le site de Mleiha dans l'actuel émirat de Charjat a révélé la présence de fibres et de graines de coton (Kerfant \& Dabrowski, communication 2017).

témoignage extérieur de la stèle d'Ezana (ca 325-356), et l'archéologie a confirmé cette production cotonnière et son tissage sur place à l'époque méroïtique (Gervers 1999 : 13-30; Bouchaud et al. 2018; Yvanez \& Wozniak, ce volume). Le coton ne disparaît cependant pas par la suite car à l'époque médiévale, il est encore vu par un voyageur arabe en Nubie au $\mathrm{x}^{\mathrm{e}}$ siècle (Adams 2018; voir également Yvanez \& Wozniak, ce volume). Al-Uswānī précise en effet que le coton y est cultivé et que ses habitants en font des vêtements grossiers et bon marché (El-Hag 1989 : 48).

\section{La diffusion de la plante à l'époque médiévale}

En revanche, pour l'Afrique du Nord, par manque de sources, les dynamiques sont moins nettes, et il n'est pas invraisemblable ici que la culture du coton soit passée par les oasis égyptiennes, que l'on sait en contact avec la Tripolitaine et l'Ifrīqiya du viII ${ }^{\mathrm{e}}$ au $\mathrm{IX}^{\mathrm{e}}$ siècle. Cependant, les quelques allusions que l'on a sur ces relations tribales ou commerciales ne mentionnent pas le coton. Il y a néanmoins assez de coton dans l'actuelle Tunisie pour qu'en août 947 la dépouille d'un rebelle en soit bourrée et livrée à des singes par dérision. On ne sait si c'était un coton alors produit sur place ou 
d'importation (Prévost 2008 : 353-354). Au XI ${ }^{\mathrm{e}}$ siècle, al-Bakrī (m. 1094) fait état, en Afrique de l'ouest, d'une petite mais régulière production de coton alors qu'il mentionne des étoffes de coton comme monnaie d'échanges avec les Maghrébins. Sur la côte méditerranéenne, une production cotonnière est décrite à Barqa et à Gafsa au XII siècle qui, elle, est exportée même au sud du Sahara; il semble cependant que les conditions climatiques n'aient pas été aussi favorables au Maghreb pour une production intensive (Thiry $1995:$ 179, 237, 368, 483 ; Lombard 2002 : 71-75).

En Andalous, il faut attendre le $x^{e}$ siècle pour qu'un calendrier agricole nous apprenne que le coton est semé en mars ('Arïb ibn Sa'd, Calendrier de Cordoue).

On rappellera ici la séduisante hypothèse de Richard Bulliet qui considère que le développement de la culture du coton sur le plateau iranien après la conquête musulmane et surtout aux $\mathrm{IX}^{\mathrm{e}}$ et $\mathrm{x}^{\mathrm{e}}$ siècles est dû à la conjonction de trois facteurs. D'abord l'existence de pratiques locales préislamiques, vivifiées alors par le droit musulman médiéval qui est favorable à la remise en culture de terres et par la présence d'un capital financier qu'une élite urbaine était prête à investir. Cette production aurait été finalement encouragée par l'extension de modes vestimentaires où le coton était favorisé. Cela expliquerait l'expansion des cotonnades tant comme produit domestique que comme bien d'un commerce à longue distance, avant un déclin de sa production en Iran, à cause d'un refroidissement climatique notable de la fin du $\mathrm{x}^{\mathrm{e}}$ siècle au XII siècle (Bulliet 2009: 42-68). Si les premiers éléments de la démonstration sont acceptés, l'engouement et surtout les causes du déclin de la production restent à démontrer.

\section{Les activités professionnelles}

\section{Botanique et agronomie}

Le plus ancien ouvrage à contenu agricole tardo-antique qui traite du coton au ProcheOrient est l'Agriculture nabatéenne, vaste compilation réalisée en Iraq entre les $\mathrm{III}^{\mathrm{e}}$ et $\mathrm{V}^{\mathrm{e}}$ siècles, et passée en arabe au $\mathrm{x}^{\mathrm{e}}$ siècle par Ibn Wahšiyya. Si la chronologie de sa composition reste floue, elle montre parfaitement l'état des connaissances et des pratiques en basse Mésopotamie, soit l'actuel Iraq. L'ouvrage consacre ainsi un court chapitre à la culture du coton et à son usage médical, ce qui nous ne retiendra pas ici. On apprend ainsi que la plante à maturité atteint au moins la taille d'un homme. Ses branches sont fines et le coton se trouve dans des capsules rondes qui, fendues, donnent le coton. Il est semé fin avril (nīsān) et arrive à maturité fin juillet (hazīrān). On peut retarder sa plantation jusqu'à la mi-mai (ayyār). Les gens des basses terres avancent sa plantation à début avril et ils le récoltent en juillet (tammūz) et août (āb). Il est de première qualité, sa capsule ronde n'a pas encore atteint sa pleine maturité, mais on le ramasse sans problème, c'est le meilleur. Par ailleurs, c'est un arbuste qui grandit vite mais qui a alors un besoin vital d'eau (Ibn Wahšiyya, Agriculture nabatéenne, éd. 1993: 520-521). Une remarque du même ouvrage avance que le coton pouvait entrer dans la composition de farine comestible (Hämeen-Anttila 2006 : 336).

Le premier botaniste à évoquer le coton est Abū Ḥanīfa al-Dīnāwarī (m. 895) qui écrit :

«Un nomade de la tribu des Kalb m'a rapporté que le coton grandissait chez eux sous la forme d'un arbre jusqu'à atteindre la taille de l'abricotier et il reste ainsi vingt ans. Il poursuit : le meilleur est celui qui est jeune, planté l'année même. On appelle celui d'un an (al-qawr) et le plus vieux al-qașm, il est complétement dur » 
(al-Dīnāwarī, Dictionnaire botanique, éd. 1973 : 217-218 ; description reprise par Ibn Bayțār, Al-ğāmi li-ma'rifat al-adwiya wa-l-aǵdiya [s.d.] : II, 271). or, une traduction de l'Historia plantarum de ce dernier est attribuée à un certain Ibrāhīm ibn Bakūs (VIII ${ }^{\mathrm{e}}$ siècle) sous le titre du K. asbāb al-nabāt, mais elle est perdue (Sezgin 1971: IV, 313). Il se pourrait dès lors que cette comparaison remontant à Théophraste soit passé chez Abū Ḥanïfa par transmission textuelle et non réellement dans le témoignage du bédouin.

31 Un calendrier arabe, irakien, de la première moitié $\mathrm{du} \mathrm{IX}^{\mathrm{e}}$ siècle, celui de Jean de Māsawayh, indique que l'on sème le coton en janvier. Certes, l'auteur compile dans ce calendrier des informations de sources différentes et la date qu'il donne ne signifie pas qu'elle vaut nécessairement pour l'Irak. On notera qu'il est contemporain d'Abū Hanīfa al-Dinawarī (Troupeau 1962 : 122). Il est à remarquer qu'un dār al-quṭn ou « maison du coton » est connu à Baghdad au x $\mathrm{x}^{\mathrm{e}}$ siècle, ce qui confirme la vente de balles de coton, la production de vêtements en coton ou simplement un endroit où il est traité dans la capitale abbaside (Serjeant $1972: 25$ ). monde musulman, exception faite d'al-Andalus, de la Sicile et de l'Égypte où ses attestations sont alors rares (Miquel 1975 : 432, note 3). À partir de son apparition au x $x^{e}$ siècle en Andalous, les agronomes de cette région commencent alors décrire sa culture, comme Abū l-Khayr al-Shağğār («l'Arboriculteur») qui, après avoir décrit la préparation de la terre, présente le semi de la manière suivante :

"On plante chaque grain isolément ou on sème à la volée, de manière à ce que chacune soit espacée d'à peu près un empan. Dans le dernier cas, la semence doit être débarrassée du duvet qui l'entoure ordinairement afin que la dissémination puisse s'effectuer de manière uniforme. Pour cela, on humecte la graine, puis on la tasse avec de la terre sèche pulvérisée, ou de la poussière de fumier. Elle se débarrasse ainsi de tout son duvet, et l'on peut être assuré que les grains ne resteront pas adhérents les uns aux autres. Après l'ensemencement, on arrose jusqu'à ce que la tige du cotonnier soit sortie de terre. (...). On reprend les arrosages, que l'on maintient jusqu'au commencement du mois d'août en ayant soin, après chaque irrigation, de ramener la terre au pied de la plante, pour la garantir de la sécheresse. (...). La récolte du coton se fait en septembre » (Abū lHayr, Kitāb al-filāha, éd. 1946 : 26-27).

Ces mêmes recommandations, augmentées de quelques autres se retrouvent dans le manuel d'agriculture (Kitāb al-filāha) d'Ibn Bașșāl (Ibn Bașșāl, Libro de agricultura, éd. 1995 : ar. 114-116/tr. 151-153), agronome andalous actif dans la deuxième moitié du XI siècle qui indique aussi que le cotonnier est cultivé en Sicile et en Syrie. Toujours en Andalousie, Ibn al-'Awām, au XIII ${ }^{\mathrm{e}}$ siècle, consacre à sa culture un chapitre où il détaille les pratiques d'ensemencement, de plantation et d'irrigation dans la péninsule ibérique et en Syrie. On y apprend aussi incidemment qu'il était cultivé au Hiǧăāz (Arabie) (Ibn al-'Awām, Livre de l'agriculture, éd. 1866: 101-106). Enfin, toujours en Andalousie, Ibn Luyūn (m. 1349), consacre un poème de son manuel d'agriculture versifié au coton (Ibn Luyūn, Tratado de agricultura, éd. $1988: 156)$ :

« Pour le coton, il faut environ faire sept labours à la charrue à la surface du sol et la graine est mise un peu à tremper. L'irrigation se fera chaque semaine et les [parties] sarclées donneront un fruit de bonne qualité. Tous les jours de la semaine, en matinée, le coton est cueilli de son cocon ouvert. Il est alors déposé au soleil pour être séché, et après avoir été prélevé, [le coton] est filé. Dans sa culture, on peut 
mêler un peu de fumier de mouton pour que [la plante] porte un dense duvet. Ces semis se font à la main, trois ou quatre plants étant plantés dans des larges sillons, comme on fait avec le melon et le concombre, ainsi le coton fleurira et donnera des fruits nouveaux. Traitées de la sorte plusieurs années, on récoltera [des plantes] un coton bien visible». dans certains ateliers textiles de métropoles musulmanes et dont la production relevait parfois d'un monopole d'État car ces textiles étaient chers, précieux et étaient parfois donnés par le pouvoir comme gratification. Ces textiles particuliers portent le nom de țirāz. Les tịrāz aujourd'hui conservés confirment une expansion du coton mais plus on s'éloigne du nord-est de l'Iran pour se diriger vers l'Égypte, moins le coton est présent. Ainsi les exemples provenant de Nishapour du début du $x^{e}$ siècle sont en coton (fils de chaîne et de trame), à la même époque les ateliers d'Iraq tissent des tissus métis, de lin et de coton, alors que les ateliers égyptiens tissent quasi exclusivement du lin. Les collections muséales de textiles musulmans présentent des pièces en coton et celles-ci sont généralement originaires du Yémen ou de Mésopotamie, comme en témoignent certaines inscriptions qui les marquent. Le Textile museum de Washington possède un țirāz en coton des années 866-869 (Kühnel \& Bellinger 1952: 9, 110-120). Le musée de Boston garde un țirāz tissé en Mésopotamie sur coton daté de 932 (Britton $1938: 30$ ). Le Metropolitan Museum of Art possède une série de pièces tissées en coton du IX siècle, dont une porte une inscription mentionnant le fils du calife abbaside al-Mustanșir (r. 861-863) qui fut gouverneur de plusieurs provinces en Arabie dont le Yémen (Walker \& Froom 1992 : 14-15). Le musée arabe du Caire garde un țirāz en coton tissé à Sana'a en 923 tandis que le Museum of fine arts de Boston possède plusieurs pièces des $\mathrm{IX}^{\mathrm{e}}$ et $\mathrm{X}^{\mathrm{e}}$ siècles de même provenance (Britton 1938: 73). Enfin, dans les fouilles de Fusțât, dirigées par R.-P. Gayraud, ont été mis au jour, dans les cercueils des Fatimides, de magnifiques țirāz, probablement tissés en Irak dans la deuxième moitié du $\mathrm{x}^{\mathrm{e}}$ siècle (Gayraud 1994).

Une fois installée dans les pays de la Méditerranée musulmane au $\mathrm{x}^{\mathrm{e}}$ siècle, la culture du coton passe au monde chrétien, pour atteindre la Grèce continentale, les îles égéennes, Chypre et l'Italie du Sud (Nam 2007 : 97-106).

\section{La vente}

Un manuel de marchand syrien $\mathrm{du} \mathrm{XI}^{\mathrm{e}}$ siècle, donne des informations sur la pratique de la vente du coton avant son filage. Il indique que : 
«On reconnaît la qualité du coton dans la justesse de sa pesée. Une très grande légèreté indique un petit nombre de grains (habb). Lors de l'examen, [on fera attention] à la blancheur, au fait qu'il soit débarrassé de "l'écorce " (qishra), à la facilité à le diviser et lors du toucher, [on sera] attentif à la mollesse (wața'a) et à la douceur » (al-Dimašqī, Al-ishāra ilā maḥāsin al-tiğāra, éd. 1999 : 38).

Dans des manuels de contrôle des marchés (hisba), des prescriptions relatives à la vente du coton apparaissent également. Ainsi à Damas, au xIII siècle, al-Šayzarī précise que les cotonniers

\begin{abstract}
«ne mélangeront pas le coton neuf avec l'ancien, ni le rouge avec le blanc. Il convient que le coton soit aéré (yundafu, litt. « secoué ») de manière répétée jusqu'à ce que l'écorce noire s'en envole et que la graine soit brisée car, s'il en reste, elle apparaîtra à la pesée. Si ce coton est jeté dans un drap, une ğubba (vêtement d'homme ouaté) ou une qabbā' (vêtement masculin avec des manches), les souris les rongeront. On ne mêlera pas ce qu'il y a au bas de la pierre à égrener (basața) avec ce qui est sain et ce qui s'envole sur les murs du coton de qualité. Parmi les artisans, certains aèrent le coton de mauvaise qualité rouge et le placent au bas de la boule (kubba) et ensuite ils la grossissent avec le coton blanc propre, il n'apparaît que lors du tissage. Le prévôt des marchés (muhtasib) leur défendra de faire asseoir les femmes à la porte de leurs boutiques pour voir l'achèvement du filage et il leur défendra de parler avec elles. Ils ne déposeront pas le coton une fois filé dans des endroits humides car cela augmente son poids. Et quand il sèche, il en perd. C'est une tromperie qu'ils font tous, et le prévôt le leur interdira » (Al-Šayzarī, Nihāyat alrutba fi țalab al-hisba, éd. 2014 : 130).
\end{abstract}

Quant à l'Égypte, on doit reconnaître qu'avant l'an 900, aucun document arabe ne signale d'étoffes de coton produites sur place (Rāgib 1985: 25), alors même que la culture du coton est attestée en Égypte dès le $\mathrm{I}^{\mathrm{er}} / \mathrm{II}^{\mathrm{e}}$ siècle de notre ère. Par la suite, le coton brut est surtout importé de Syrie et du Maghreb, de même que les textiles de coton étaient eux-mêmes importés d'Iraq ou d'Inde, comme en témoignent les documents de la Genizah (Goitein $1967: 105-107$ et $1983: 170-171$ ). Cependant, aux XI ${ }^{\mathrm{e}}$ et $\mathrm{XII}^{\mathrm{e}}$ siècles, les vêtements en coton sont absents des trousseaux et des inventaires après décès, mais on les retrouve dans les listes relatives aux personnes venant $d u$ Maghreb ou d'Inde. Dans les lettres venant de Syrie qui y font allusion comme partie de la cargaison, le coton ne représente qu'une partie mineure, car transporter des produits bon marché, en grande quantité et en gros volumes était surtout le fait de très riches affréteurs de bateaux. À l'époque mamelouke, un marché du coton apparaît au Caire avant le $\mathrm{XII}^{\mathrm{e}}$ siècle. Le funduq al-quṭn était sujet à une taxe qui est levée par Saladin en 1169 (Serjeant $1972: 152$ ).

\title{
Conclusion
}

Le monde situé à l'ouest de l'Euphrate, a reçu la culture du coton et son usage textile depuis l'Iran, et cela dès le $\mathrm{v}^{\mathrm{e}}$ siècle si on en croit l'Agronomie nabatéenne, qui fut alors compilée en Mésopotamie et qui montre l'acclimatation parfaite de cette culture; toutefois, la plante et le textile produit étaient connus précédemment, mais de manière beaucoup plus sporadique. L'étymologie des termes arabes désignant le coton ou les textiles qui en ont été tirés est majoritairement d'origine persane, ce qui démontre que c'est bien de l'est, de l'Iran, que viennent la plante et les produits qui en furent dérivés. Comme maints autres produits, le coton a pu profiter de l'existence d'un empire qui n'avait pas de frontières de l'Iran à al-Andalous et, au xe siècle, cette plante est, selon 
les textes, cultivée dans pratiquement tout le monde musulman, exception faite d'alAndalus, de la Sicile et de l'Égypte, où ses attestations sont alors rares (Miquel 1975 : 432, note 3). Si la culture du coton et son usage textile furent, dans un premier temps, essentiellement présents à l'est du domaine arabe et musulman, ils entrèrent dans le patrimoine matériel et cultuel arabe, puisque les botanistes et les agronomes fournirent des informations sur la culture et sur plusieurs aspects de la plante, alors que les calendriers précisaient les phases de culture selon les régions où ils étaient produits.

\section{BIBLIOGRAPHIE}

Abū l-Hुayr al-Ishbilī, [Aboû'l-Khayr ach-Chadjdjâr al-Ichbîli] 1946 - Kitāb al-filāḥa, tr.

Charbonneau, A. et Pérès, H.. Alger, Carbonel, 30 p.

Adams N.K. 2018 - From cotton fields to pastures: the transition from cotton to wool clothing in Nubia. In : Honegger M. (Ed.), Nubian archaeology in the XXst century. Leuven : 597-604. (Orientalia lovaniensia ; 279).

'Addi Shir, Al-Sayyid, éd. 1990 - A dictionary of Persian Loan-words. Beyrouth, Librairie du Liban, $194 \mathrm{p}$.

Al-Dīnāwarī, Abū Ḥanīfa, éd. 1973 - Le dictionnaire botanique. Le Caire, IFAO, 447 p.

Al-Dimašqī Ǧa'far ibn ‘Alī, éd. 1999 - Al-ishāra ilā maḥāsin al-tiğāra. Beyrouth, Dār Șāder, 109 p.

Al-Muqaddasī, éd. 1906 - Aḥsan al-taqāsīm fì márifat al-aqālīm, éd. De Goeje, M. J.. Leiden, Brill, $494 \mathrm{p}$.

Al-Šayzarī, 'Ab al-Raḥmān, éd. 2014 - Nihāyat al-rutba fi țalab al-ḥisba. Freiberg, Al-Kamel, 255 p.

Al-Tha'ālabī, éd. 1968 - The Book of Curious and Entertaining Information, (tr.) Bosworth, C. E.

Edinburgh, The University Press, $164 \mathrm{p}$.

Bagnall R.S. 1997 - The Kellis Agricultural Account Book. Oxford, Oxbow, 253 p.

Baker L.P. 1995 - Islamic textiles. London, British Museum Press, 1992 p.

Beaulieu P.-A. 1989 - “Textes administratifs inédits d'époque hellénistique provenant des archives de Bīt Rēš". Revue d'assyrologie, 83 : 53-87.

Boardman S. 1999 - The agricultural foundation of the Aksumite Empire, Ethiopia: an interim report. In : Van der Veen M. (Ed), The Exploitation of Plant Resources in Ancient Africa. New York Kluwer Academic, New York : 137-147.

Bouchaud C. 2015 - Al-Qutun. Importation des produits et introduction de la culture en Méditerranée. In : Richarté C., Gayraud R.-P. \& Poisson J.-M., Héritages arabo-islamiques dans l'Europe méditerranéenne. Paris, La Découverte : 315-331.

Bouchaud C., Clapham A., Newton C., Tallet G. \& Thanheiser U. 2018 - Cottoning on to Cotton (Gossypium spp.) in Arabia and Africa during Antiquity. In : Mercuri A.M., D’Andrea A.C., 
Fornaciari R. \& Höhn A. (Ed.) Plants and People in the African Past: Progress in African Archaeobotany. Springer International Publishing, Cham : 380-426.

Britton N.P. 1938 - A Study of some Early Islamic Textiles in the Museum of Fine Arts. Boston. Boston, The Museum of Fine Arts, $89 \mathrm{p}$.

Brzuski W.K. 1974 - Arabic loanwords in Amharic connected with textiles, leather products and jewelery. Africana Bulletin 20 : 63-72.

Bulliet R.W. 2011 - Cotton, Climate and Camels in Early Islamic Iran. New York, Columbia University Press, $167 \mathrm{p}$.

Ciancaglini C.A. 2008 - Iranian loanwords in Syriac. Wiesbaden, Harrassowitz, 315 p.

Cortopassi R. \& Gayraud R.-P. 2008 - Un fragment d'Istabl 'Antar et les tapis de Fustat. Annales Islamologiques $42: 299-312$.

Dozy R. 1881 - Supplément aux dictionnaires arabes. Leiden, Brill, 2 vols.

El-Hag H. M. Kh. 1989 - A Contribution to a Textual Problem: 'Ibn Sulaym al-Aswāni'sKitāb Akhbār al-Nūba wa-l-Maqurra wa-l-Beja wa-l-Nīl'. Arabica 36 : 36-80.

Fraenkel S. 1886 - Die Aramäischen Fremdwörter. Leiden, Brill, 327 p.

Gayraud R.-P. 1994 - Isțabl 'Antar (Fostat) 1992. Rapport de fouilles. Annales Islamologiques 28 : $1-27$.

Gervers M. 1990 - Cotton and cotton weaving in Meroitic Nubia and Medieval Ethiopia. Textile history $21: 13-30$.

Gignoux Ph. 2011 - Lexique des termes de la pharmacopée syriaque. Paris, Association pour l'avancement des études iraniennes, $113 \mathrm{p}$.

Goitein Sh. D. 1967 et 1983 - A Mediterranean Society, I et IV, Berkeley, University of California Press, 550 p. et 487 p.

Hämeen-Anttila J. 2006 - The Last Pagans of Iraq. Ibn Wahshiyya and his Nabatean Agriculture. Leiden, Brill, 396 p.

Ibn al-'Awām, éd. 1866 - Le Livre de l'agriculture, II/1, (tr.), Clement-Mulet J.-J. Paris, A. Franck, $460 \mathrm{p}$.

Ibn Bașșāl, éd. 1995 - Libro de agricultura, tr. Sánchez G., Esteban J. et Bermejo H. Tétouan, Genade, El legado Andalusí.

Ibn Bayțār, Al-ǧāmi‘ li-ma'rifat al-adwiya wa-l-aǵdiya, Beirout, Dār al-kutub al-'ilmiyya, 2 vols. Ibn Ḥawqal, éd. 1939 - Kitāb șūrat al-arḍ, éd. Kramers. Leiden, Brill, 528 p.

Ibn Luyūn, éd. 1988 - Tratado de agricultura, éd. et tr. Ibáñez J. E. Patronato de la Alhambre y Generalife, 302 p.

Ibn Manẓūr, éd. 1997 - Lisān al-'Arab, Beirut, Dār iḥyā’ al-turāth, 18 vols.

Ibn Wahšiyya, éd. 1993 - Agriculture nabatéenne, éd. Fahd, T. Damas, Institut français de Damas, 2 vols.

Klein E. 1987 - A Comprehensive Etymological Dictionary of the Hebrew Language. New York, Macmillan, $721 \mathrm{p}$.

Kühnel E. \& Bellinger L. 1952 - Catalogue of Dated Tiraz Fabrics. Washington D.C., National Publishing Company, $137 \mathrm{p}$. 
Lombard M. 2002 - Les textiles dans le monde musulman du VIIe au XIIe siècle. Paris, Editions de l'EHESS, $311 \mathrm{p}$.

Löw I. 1924 - Die Flora der Juden. Iridaceae - Papilionaceae. Wien, 532 p.

MacKenzie D.N. 1971 - A Concise Dictionary of Pahlavi. Oxford, University Press, 264 p.

Marco Polo, éd. 2011 - Le devisement du monde. Le livre des merveilles. Paris, La Découverte, 554 p.

Miquel A. 1975 - La géographie humaine du monde musulman jusqu'au milieu du 11e siècle. Géographie arabe et représentation du monde: la terre et l'étranger. Paris, Mouton, 705 p.

Miquel A. 1980 - La géographie humaine du monde musulman jusqu'au milieu du 11e siècle. Le milieu naturel. Paris, Mouton, 543 p.

Muthukumaran T. 2016 - Tree cotton (G. arboreum) in Babylonia. In : Foietta E. et al. (Ed.), Cultural and Material Contacts in the Ancient Near East. Florence : 98-108.

Nam J.-K. 2007 - Le commerce du coton en Méditerranée à la fin du Moyen Âge. Leiden, Brill, 367 p.

Pellat Ch. 1986 - Cinq calendriers égyptiens. Le Caire, IFAO, 275 p.

Rāgib Y. 1985 - Marchands d'étoffes au Fayyoum au IIIe/IXe siècle. Le Caire, IFAO, 69 p.

Rolland J.-Cl. 2016 - Etymologie arabe. Paris, L’Asiathèque, 205 p.

Serjeant R. P. 1972 - Islamic Textiles. Material for a History up to the Mongol Conquest. Beirut, Librarie du Liban, 263 p.

Schafer E. H. 1985 - The golden peaches of Samarkand. A study of T'ang exotics. Berkeley, University of California Press.

Sezgin F. 1971 - Geschichte des arabischen Schrifttums. Band 4. Leiden, Brill, 398 p.

Sokoloff M. 2009 - A Syriac Lexicon. Indiana, Gorgias Press, 1738 p.

Tengberg M. \& Lombard P. 2001 - Environnement et économie végétale à Qal'at Bahrein aux époques de Dilmoun et Tylos. Premiers éléments paléobotaniques. Paléorient 17/1 : 167-181.

Théophraste, éd. 1989 - Recherches sur les plantes, éd. et tr. Amigues. Paris, Les Belles Lettres, $304 \mathrm{p}$.

Thiry J. 1995 - Le Sahara libyen dans l'Afrique du Nord médiévale. Leuven, Peeters, 604 p.

Troupeau G. 1962 - Le livre des temps de Jean de Māsawayh. Arabica, XV/2 : 113-142.

Ullmann M. 1970 - Wörterbuch der Klassischen Arabischen Sprache. I. Kāf. Wiesbaden, Harrassowitz, $586 \mathrm{p}$.

Vallet E. 2010 - L'Arabie marchande. Paris, Publications de la Sorbonne, 871 p.

Varisco D.M. 1991 - A royal crop register from Rasulid Yemen. JESHO 34 : 1-22.

Walker D.S. \& Froom A. 2002 - Exhibition Notebook. In : Tiraz: Inscribed Textiles from Islamic Workshops. New York, NY, The Metropolitan Museum of Art.

Welsby D.A. 2002 - The medieval kingdoms of Nubia. London, The British Museum Press, 296 p.

Zawadzki St. 2006 - Garments of the gods: Studies on the Textile Industry and the Pantheon of Sippar according to the Texts from the Ebabbar Archive. Fribourg, $254 \mathrm{p}$. 


\title{
RÉSUMÉS
}

Les sources médiévales arabes qui relèvent de la littérature technique indiquent une lente mais continuelle progression du coton depuis le domaine iranien dans la direction de l'ouest, avec néanmoins d'importantes variations régionales. L'essentiel des termes qui désignent la plante et ses produits sont des emprunts passés par le pehlevi mais arabisés très tôt, ce qui indique l'ancienneté de l'adoption de la fibre. A partir du $\mathrm{X}^{\mathrm{e}}$ siècle, on suit la diffusion du produit vers l'ouest, notamment au travers d'ouvrages de botanique et d'agronomie, alors que les professions liées au coton se singularisent également dans les sources, que ce soit dans le traitement de la fibre ou la vente du produit.

Technical literature of the Arab medieval sources indicates a slow but continuous progression of cotton from the Iranian region towards the West, with significant regional variations. Most of the terms used to describe the plant and its products are borrowed from Pahlavi and integrated very early in the Arabic language, which indicates the long history of the adoption of the fibre. From the 10th century onwards, botanical and agronomic works record the spread of the product towards the West and the singularisation of the professions linked to cotton, whether for the treatment of the fibre or the sale of the product.

\section{INDEX}

Mots-clés : littérature, lexicographie, islam, Moyen Age

Keywords : literature, lexicography, Islam, Middle Ages

\author{
AUTEUR \\ JEAN-CHARLES DUCÈNE \\ Directeur d'études - École Pratique des Hautes Études (EPHE) - Paris Sciences et Lettres (PSL) - \\ Section des Sciences Historiques et Philologiques - UMR 7192 Proche-Orient, Caucase, Langues, \\ Archéologie, Cultures (PROLAC) \\ jean-charles.ducene@ephe.psl.eu
}

